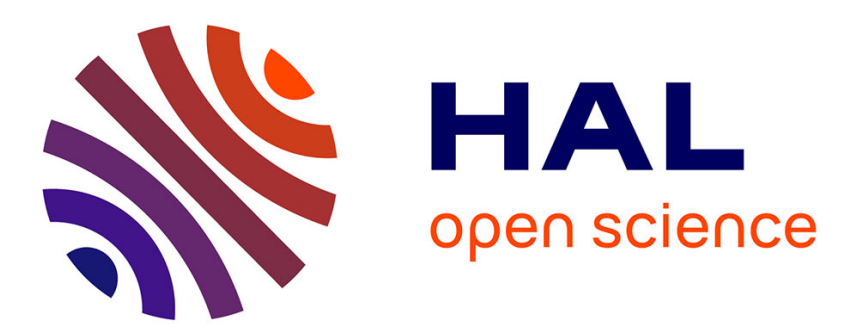

\title{
Comparison of two approaches for the discretization of elastodynamic contact problems
}

\author{
Houari Boumediène Khenous, Patrick Laborde, Yves Renard
}

\section{To cite this version:}

Houari Boumediène Khenous, Patrick Laborde, Yves Renard. Comparison of two approaches for the discretization of elastodynamic contact problems. Comptes Rendus. Mathématique, 2006, 342 (10), pp.791-796,. 10.1016/j.crma.2006.03.011 . hal-00690583

\section{HAL Id: hal-00690583 \\ https://hal.science/hal-00690583}

Submitted on 13 Jun 2016

HAL is a multi-disciplinary open access archive for the deposit and dissemination of scientific research documents, whether they are published or not. The documents may come from teaching and research institutions in France or abroad, or from public or private research centers.
L'archive ouverte pluridisciplinaire HAL, est destinée au dépôt et à la diffusion de documents scientifiques de niveau recherche, publiés ou non, émanant des établissements d'enseignement et de recherche français ou étrangers, des laboratoires publics ou privés. 


\title{
Comparison of two approaches for the discretization of elastodynamic contact problems
}

\author{
Houari Boumediène Khenous ${ }^{a}$, Patrick Laborde ${ }^{b}$, Yves Renard ${ }^{a}$ \\ a INSA Toulouse, département GMM, 135, avenue Rangueil, 31077 Toulouse cedex 4, France \\ ${ }^{\mathrm{b}}$ Université Paul-Sabatier, Laboratoire MIP, 118, route de Narbonne, 31062 Toulouse cedex 4, France
}

\begin{abstract}
The purpose of this Note is to compare two approaches for the discretization of elastodynamic contact problems. First, we introduce an energy conserving method based on a standard midpoint scheme and a contact condition expressed in terms of velocity. The second approach consists in considering an equivalent distribution of the body mass so that the nodes on the contact boundary have no inertia. We prove that this method leads to an energy conservation for the space semi-discretized elastodynamic contact problem. Finally, some numerical results are presented in the two dimensional case.
\end{abstract}

\section{Résumé}

Comparaison entre deux approches de la discrétisation du problème de contact en élastodynamique. Dans cette Note, on compare deux approches de la discrétisation du problème élastodynamique de contact. La première correspond à un schéma qui conserve strictement l'énergie du problème. Ce schéma résulte d'une méthode de point milieu standard avec une loi de contact exprimée en fonction de la vitesse. Dans la deuxième approche, on considère une distribution équivalente de la masse du corps de telle sorte que les points du bord de contact n'aient plus d'inertie. Ceci permet d'aboutir à une conservation de l'énergie pour le problème semi-discrétisé en espace. Enfin, on présente des tests numériques en dimension deux.

\section{Version française abrégée}

Le problème de contact élastodynamique semi-discrétisé en espace est décrit par le problème (1). La difficulté est que ce problème est mal posé (voir [6,7]). Pour retrouver l'unicité, une des méthodes bien adaptée aux corps rigides est l'introduction d'une loi d'impact avec un coefficient de restitution. L'approche s'avère moins satisfaisante dans le cas des corps élastiques déformables car, quelque soit le choix du coefficient de restitution, le problème (1) tend vers une restitution totale de l'énergie quand le pas d'espace tend vers zéro (voir [1] pour plus de détails). 
Dans la deuxième section, on présente une condition de contact équivalente (2) exprimée en terme de vitesse ; elle doit être comprise au sens de la dérivée à droite du déplacement. Cette loi est très proche de celle présentée dans [6] et correspond aussi à celle introduite dans [5]. De plus, on note que la deuxième condition dans (2) implique la noninterpénétration. On discrétise l'équation de l'élastodynamique en (1) par un schéma de point milieu standard pour obtenir (3). La condition (2) est approchée par la formulation (4) en utilisant un schéma de différences finies centrées. On montre alors que la stabilité du schéma (3)-(4) est assurée par le fait que l'énergie discrète (5) est conservée dans le sens où (6) est vérifiée. La différence essentielle avec le schéma présenté dans [5] est l'approximation de la condition (2) par un schéma centré aux différences finies.

Dans la section suivante, on traite la deuxième approche qui consiste à considérer une répartition de la masse du corps de telle sorte que les points du bord de contact n'aient pas d'inertie. La nouvelle matrice de masse est équivalente à la matrice de masse initiale dans le sens où on impose la conservation de la masse totale, du centre de gravité et des moments d'inertie. En effet, le caractère mal posé du problème (1) vient du fait que les points du bord de contact ont leur propre inertie. Cette approche nous permet d'obtenir un problème bien posé qui admet une solution Lipschitzienne et conserve l'énergie. Une démonstration complète de ces deux résultats sera présentée dans [1].

Enfin, on présente des résultats numériques obtenus sur des simulations de chute libre d'un disque élastique.

\section{Introduction}

For purely contact elastodynamic problems (hyperbolic problems), as far as we know, the existence result has been proved in a scalar two dimensional case by Lebeau and Schatzman [4,3] and in the vector case, with a modified contact law, by Renard and Paumier [8]. It seems that no energy conserving result has been proved in the continuous framework. These problems lead to mathematically complex models which remain to be fully understood. The analysis of contact problems is of great importance in many engineering applications. In this Note, two numerical strategies are compared. The first is a strict energy conserving scheme based on a standard midpoint scheme for the elastodynamic part and a contact law expressed in terms of velocity. In the second, we consider an equivalent mass matrix so that the corresponding finite element problem is energy conserving.

The space semi-discretization of the elastodynamic contact problem with nodal contact condition (assuming a vanishing initial gap between the structure and the rigid foundation) is defined for a Lagrange finite element method as follows:

$$
\left\{\begin{array}{l}
\text { Find } U \in] 0, T\left[\times \mathbb{R}^{d} \text { and }\left(\left(\Lambda_{N}\right)_{i}\right) \in\right] 0, T\left[\times \mathbb{R}^{m},\right. \text { satisfying } \\
M \ddot{U}+K U=L+\sum_{i \in I_{C}} \Lambda_{N}^{i} N_{i}, \quad \text { in }[0, T] \times \mathbb{R}^{d}, \\
\Lambda_{N}^{i} \leqslant 0, \quad U \cdot N_{i} \leqslant 0, \quad \Lambda_{N}^{i}\left(U \cdot N_{i}\right)=0, \quad \forall i \in I_{C}, \\
U(0)=U^{0}, \quad \dot{U}(0)=U^{1},
\end{array}\right.
$$

where $d$ is the number of degrees of freedom for the displacement $U$ and $m=\operatorname{card}\left(I_{C}\right)$ is the number of nodes on the contact boundary, the notations $M, K, L$ stand for the mass matrix, the stiffness matrix and the given force densities respectively, $I_{C}$ is the set of the contact boundary indices. On each node $i \in I_{C}$, we denote $\Lambda_{N}^{i}$ and $N_{i}$ the normal stress and the outward unit normal respectively (for more details see [2]).

The major difficulty is that problem (1) is not well posed (see [6]). To recover the uniqueness, one of the approaches well adapted to rigid bodies is to introduce an impact law with a restitution coefficient. This seems not to be completely satisfactory for deformable bodies, because whatever the restitution coefficient, the system tends to a global restitution of energy when the mesh parameter goes to zero (more details will be presented in [1]).

\section{Scheme with an equivalent contact condition in terms of velocity (ECC)}

The classical Signorini condition in problem (1) can be replaced by the following condition:

$$
\left\{\begin{array}{l}
U \cdot N_{i}<0 \Longrightarrow \Lambda_{N}^{i}=0, \\
U \cdot N_{i} \geqslant 0 \Longrightarrow \dot{U} \cdot N_{i} \leqslant 0, \Lambda_{N}^{i} \leqslant 0, \Lambda_{N}^{i}\left(\dot{U} \cdot N_{i}\right)=0 .
\end{array}\right.
$$

The expression (2) in terms of velocity is very close to the one introduced in [6] and corresponds to the one presented in [5]. The velocity is to be understood as a right derivative and the second condition in fact implies the non-interpenetration. 
The discretization we propose is based on a midpoint scheme for elastodynamic problems:

$$
\left\{\begin{array}{l}
U^{0} \text { and } V^{0} \text { given, } U^{1}=U^{0}+\Delta t V^{0}+\Delta t z(\Delta t) \text { with } \lim _{\Delta t \rightarrow 0} z(\Delta t)=0, \\
M\left(\frac{U^{n+1}-2 U^{n}+U^{n-1}}{\Delta t^{2}}\right)+K\left(\frac{U^{n+1}+2 U^{n}+U^{n-1}}{4}\right)=L+\sum_{i \in I_{C}} \Lambda_{N}^{i, n} N_{i}, \quad \forall n \geqslant 1,
\end{array}\right.
$$

where $\Delta t$ is the time parameter. The contact condition (2) is approximated using a central difference scheme:

$$
\left\{\begin{array}{l}
U^{n} \cdot N_{i}<0 \Longrightarrow \Lambda_{N}^{i, n}=0, \\
U^{n} \cdot N_{i} \geqslant 0 \Longrightarrow \frac{\left(U^{n+1}-U^{n-1}\right) \cdot N_{i}}{2 \Delta t} \leqslant 0, \quad \Lambda_{N}^{i, n} \leqslant 0, \quad \Lambda_{N}^{i, n}\left(\frac{\left(U^{n+1}-U^{n-1}\right) \cdot N_{i}}{2 \Delta t}\right)=0 .
\end{array}\right.
$$

Theorem 2.1. The stability of scheme (3), (4) is ensured by the fact that the discrete energy

$$
J(U, V)=\frac{1}{2}\langle M V, V\rangle+\frac{1}{2}\langle K U, U\rangle-\langle L, U\rangle
$$

is conserved in the following sense:

$$
\Delta J=J\left(U^{n+\frac{1}{2}}, V^{n+\frac{1}{2}}\right)-J\left(U^{n-\frac{1}{2}}, V^{n-\frac{1}{2}}\right)=0,
$$

with $U^{n+\frac{1}{2}}=\left(U^{n+1}+U^{n}\right) / 2, V^{n+\frac{1}{2}}=\left(U^{n+1}-U^{n}\right) / \Delta t$.

Proof. One has

$$
\Delta J=\frac{1}{2}\left\langle M\left(V^{n+\frac{1}{2}}+V^{n-\frac{1}{2}}\right), V^{n+\frac{1}{2}}-V^{n-\frac{1}{2}}\right\rangle+\frac{1}{2}\left\langle K\left(U^{n+\frac{1}{2}}+U^{n-\frac{1}{2}}\right), U^{n+\frac{1}{2}}-U^{n-\frac{1}{2}}\right\rangle-\left\langle L, U^{n+\frac{1}{2}}-U^{n-\frac{1}{2}}\right\rangle .
$$

Then, using the definition of $U^{n+\frac{1}{2}}$ and $V^{n+\frac{1}{2}}$, we obtain:

$$
\begin{aligned}
\Delta J= & \frac{1}{2 \Delta t^{2}}\left\langle M\left(U^{n+1}-2 U^{n}+U^{n-1}\right), U^{n+1}-U^{n-1}\right\rangle \\
& +\frac{1}{8}\left\langle K\left(U^{n+1}+2 U^{n}+U^{n-1}\right), U^{n+1}-U^{n-1}\right\rangle-\frac{1}{2}\left\langle L, U^{n+1}-U^{n-1}\right\rangle .
\end{aligned}
$$

Hence, from (3):

$$
\Delta J=\frac{1}{2}\left\langle\sum_{i \in I_{C}} \Lambda_{N}^{i, n} N_{i}, U^{n+1}-U^{n-1}\right\rangle=\Delta t \sum_{i \in I_{C}} \Lambda_{N}^{i, n}\left(\frac{U^{n+1} \cdot N_{i}-U^{n-1} \cdot N_{i}}{2 \Delta t}\right) .
$$

Finally, (4) leads to $\Delta J=0$.

The major difference between our scheme (3), (4) and that proposed in [5] is that the contact condition (2) is discretized using a central difference scheme.

\section{Equivalent mass matrix method (EMM)}

The non-well-posedness of problem (1) comes from the fact that the nodes on the contact boundary have their own inertia. This leads to instabilities, especially for energy conserving schemes. We propose here to introduce a new distribution of the mass with the same total mass, center of gravity and inertia momenta. This distribution of mass is done so that there is no inertia for the contact nodes (similarly to what happens in the continuous case). We refer the reader to [1] for further details. We assume that the modified mass matrix is still denoted $M$ such that $N_{i}^{\mathrm{T}} M N_{j}=0$, $\forall i, j \in I_{C}$. Then, the two following results hold:

Theorem 3.1. We suppose the load vector $L$ be a Lipschitz continuous function on $[0, T]$. Then, problem (1) with the equivalent mass matrix is well-posed and has a Lipschitz continuous solution. 
Proof. If we order the degrees of freedom such that the last ones are the nodes on the contact boundary, we can split each matrix and vector in interior part and contact boundary part as follows:

$$
M=\left(\begin{array}{cc}
\bar{M} & 0 \\
0 & 0
\end{array}\right), \quad K=\left(\begin{array}{cc}
\bar{K} & C^{\mathrm{T}} \\
C & D
\end{array}\right), \quad L=\left(\begin{array}{c}
\bar{L} \\
\tilde{L}
\end{array}\right), \quad N_{i}=\left(\begin{array}{c}
0 \\
\widetilde{N}_{i}
\end{array}\right) \quad \text { and } \quad U=\left(\begin{array}{c}
\bar{U} \\
\widetilde{U}
\end{array}\right) .
$$

So, problem (1) becomes:

$$
\left\{\begin{array}{l}
\text { Find } \left.U=\left(\begin{array}{c}
\bar{U} \\
\widetilde{U}
\end{array}\right) \in\right] 0, T\left[\times \mathbb{R}^{d} \text { and }\left(\left(\Lambda_{N}\right)_{i}\right) \in\right] 0, T\left[\times \mathbb{R}^{m},\right. \text { satisfying } \\
\bar{M} \ddot{\bar{U}}+\bar{K} \bar{U}=\bar{L}-C^{\mathrm{T}} \widetilde{U} \\
C \bar{U}+D \widetilde{U}=\tilde{L}+\sum_{i \in I_{C}} \Lambda_{N}^{i} \widetilde{N}_{i} \\
\Lambda_{N}^{i} \leqslant 0, \quad U \cdot N_{i} \leqslant 0, \quad \Lambda_{N}^{i}\left(U \cdot N_{i}\right)=0, \quad \forall i \in I_{C} \\
U(0)=U^{0}, \quad \dot{U}(0)=U^{1}
\end{array}\right.
$$

The second equation, together with the contact condition, uniquely define $\widetilde{U}$ as soon as $\bar{U}$ is given. Of course, the following system:

$$
\left\{\begin{array}{l}
C \bar{U}+D \tilde{U}=\tilde{L}+\sum_{i \in I_{C}} \Lambda_{N}^{i} \widetilde{N}_{i}, \\
\Lambda_{N}^{i} \leqslant 0, \quad U \cdot N_{i} \leqslant 0, \quad \Lambda_{N}^{i}\left(U \cdot N_{i}\right)=0, \quad \forall i \in I_{C},
\end{array}\right.
$$

can be written in the following variational form:

$$
b(\widetilde{U}, V-\widetilde{U})-l(V-\widetilde{U}) \geqslant 0, \quad \forall V \in K_{N},
$$

where

$$
b(\widetilde{U}, V)=V^{\mathrm{T}} D \tilde{U}, \quad l(V)=\widetilde{V}^{\mathrm{T}} \tilde{L}-\widetilde{V}^{\mathrm{T}} C \bar{U} \quad \text { and } \quad K_{N}=\left\{V: V \cdot N_{i} \leqslant 0\right\} .
$$

We suppose that problem (7) has two solutions $U_{1}$ and $U_{2}$, and using the previous variational form and its properties, we find: $\left\|\widetilde{U}_{1}-\widetilde{U}_{2}\right\| \leqslant c\left\|\bar{U}_{1}-\bar{U}_{2}\right\|$. Then $\widetilde{U}(\bar{U})$ is Lipschitz continuous.

Furthermore, the first equation of the system (7) is a second order Lipschitz continuous ordinary differential equation, easy to solve ( $\bar{U}$ as unknown). Finally, problem (7) has a Lipschitz continuous solution.

Proposition 1. We have $\Lambda_{N}^{j} \in W^{1, \infty}([0, T], \mathbb{R})$ and $\Lambda_{N}^{j}\left(\dot{U} \cdot N_{j}\right)=0$, a.e. on $[0, T]$.

Proof. Using the first equation of system (7), we have $\bar{U}_{j} \in C^{2}([0, T], \mathbb{R})$. Also, using proof of Theorem 3.1, we obtain $\widetilde{U}_{j} \in W^{1, \infty}([0, T], \mathbb{R})$. This implies that $\Lambda_{N}^{j} \in W^{1, \infty}([0, T], \mathbb{R})$, taking in account the second equation of (7). The contact condition implies that $\Lambda_{N}^{j}=0$ on $\operatorname{Supp}\left(U \cdot N_{j}\right)=\omega_{j} \subset[0, T]$. This leads, on the one hand, that the continuity of $\Lambda_{N}^{j}$ on $[0, T]$ implies $\Lambda_{N}^{j}=0$ on $\overline{\omega_{j}}$, and on the other hand, that $\dot{U} \cdot N_{j}=0$ on $[0, T] / w_{j}$. Hence $\Lambda_{N}^{j}\left(\dot{U} \cdot N_{j}\right)=0$, a.e. on $[0, T]$.

Theorem 3.2. Problem (1) with the equivalent mass matrix is energy conserving.

Proof. The discrete energy of the system (1) is given by:

$$
E(t)=\frac{1}{2}\langle M \dot{U}, \dot{U}\rangle+\frac{1}{2}\langle K U, U\rangle-\langle L, U\rangle,
$$

where $M$ is the modified mass matrix. We want to prove that $E(t)=E(0), \forall t \in[0, T]$.

Multiplying the first equation of (1) by $\dot{U}$ and after integrating on $s$ between 0 and $t$, we obtain:

$$
E(t)=E(0)+\sum_{i \in I_{C}} \int_{0}^{t} \Lambda_{N}^{i} \dot{U} \cdot N_{i} \mathrm{~d} s, \quad \forall t \in[0, T] .
$$

Thanks to Proposition 1, we can conclude the proof. 
Table 1

Characteristics of elastic disc and solution method

\begin{tabular}{llll}
\hline Disc properties & Values & Properties of solution method & Values \\
\hline$\rho$, diameter & $6 \times 10^{3} \mathrm{~kg} / \mathrm{m}^{3}, 0.2 \mathrm{~m}$ & time parameter & $10^{-3} \mathrm{~s}$ \\
Lamé coefficients & $\lambda=10^{6} \mathrm{P}, \mu=5 \times 10^{5} \mathrm{P}$ & time of simulation & $0.3 \mathrm{~s}$ \\
$u^{0}, v^{0}$ & $0.01 \mathrm{~m},-0.1 \mathrm{~m} / \mathrm{s}$ & Mesh parameter & $\simeq 0.02 \mathrm{~m}$ \\
\hline
\end{tabular}
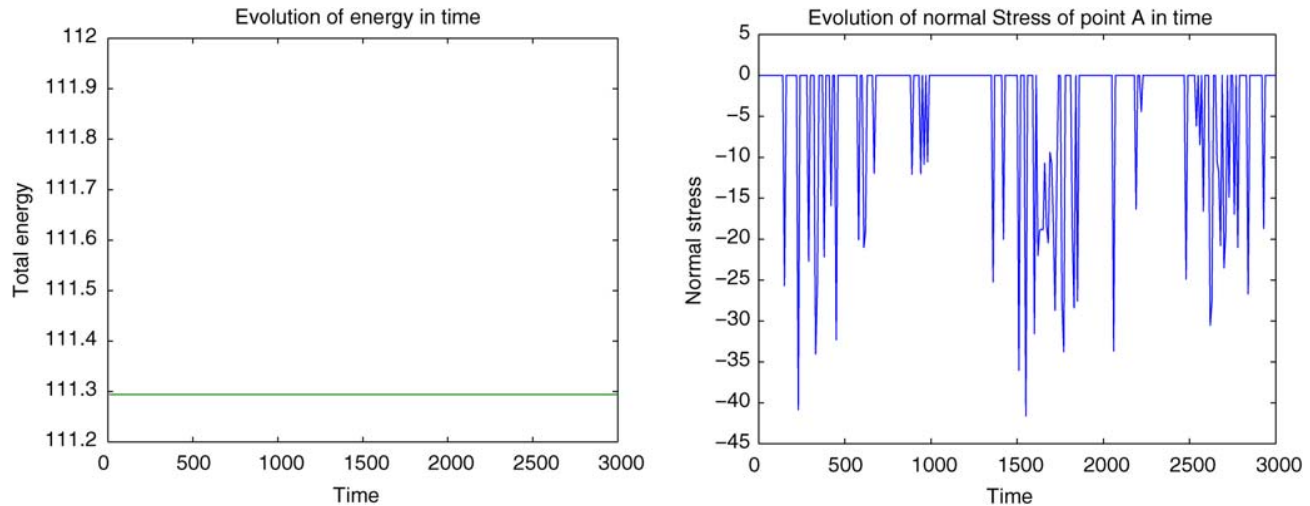

Fig. 1. Energy and normal stress evolution for the midpoint scheme with ECC condition.
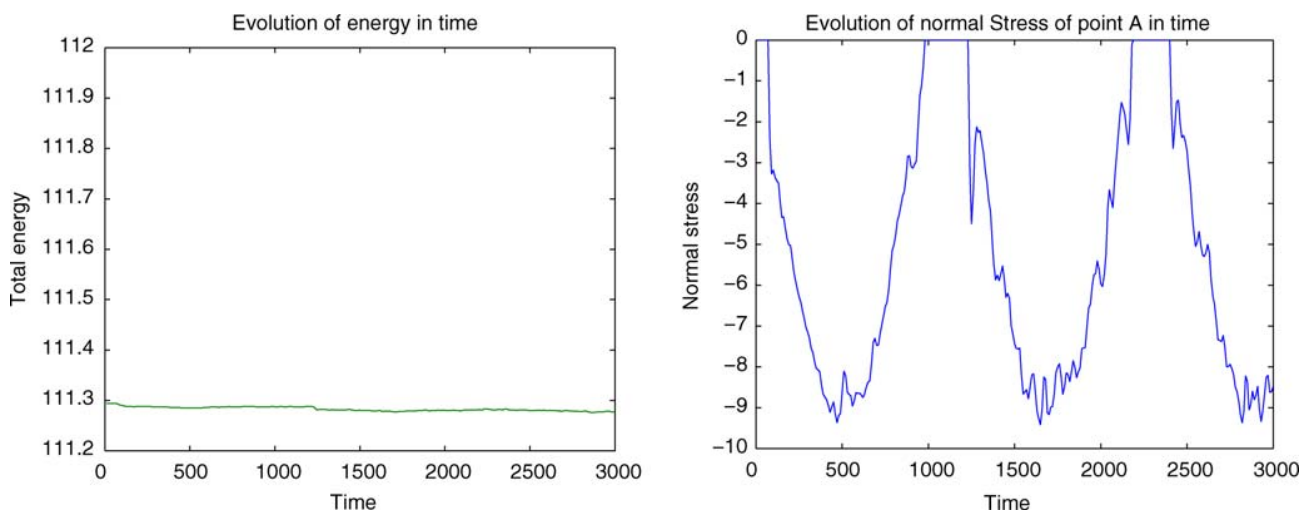

Fig. 2. Energy and normal stress evolution for the Newmark scheme with EMM method.

\section{Numerical results}

In this section, we study the dynamic contact of an elastic disc the properties of which are summarized in Table 1. We denote $A$ the lowest point of the disc (the first point which will be in contact).

The results of simulations for the midpoint scheme with the equivalent contact condition ECC are presented in Fig. 1. The energy is indeed constant; however, the normal stress in point $A$ is very noisy and inexploitable. Concerning problem (1) with a modified mass matrix, the simulations are made using a Newmark scheme with $\beta=\gamma=0.5$. Fig. 2 shows that the normal stress in $A$ for the second approach is more regular than for the first. Moreover, there are very small fluctuations in the energy evolution which are quasi-conserved.

\section{Concluding remarks}

The first approach presented ensures conservation of energy but allows a small interpenetration and the computed normal stress is badly approximated. It could be interesting to see whether or not this scheme is well adapted for rigid bodies. The second approach is very simple to implement and gives a good approximation of normal stress. For 
both approaches, adding a Coulomb friction condition is not a difficulty from the stability view point. However, this condition could be badly approximated for the first approach because it depends on the normal stress.

\section{References}

[1] H.B. Khenous, PhD thesis, INSA de Toulouse, November 2005.

[2] H.B. Khenous, J. Pommier, Y. Renard, Hybrid discretization of the Signorini problem with Coulomb friction. Theoretical aspects and comparison of some numerical solvers, Appl. Numer. Math. 56 (2) (2006) 163-192.

[3] J.U. Kim, A boundary thin obstacle problem for a wave equation, Comm. Partial Differential Equations 14 (8-9) (1989) 1011-1026.

[4] G. Lebeau, M. Schatzman, A wave problem in a half-space with a unilateral constraint at the boundary, J. Differential Equations 55 (1984) 309-361.

[5] T.A. Laursen, V. Chawla, Design of energy conserving algorithms for frictionless dynamic contact problems, Int. J. Numer. Methods Engrg. 40 (1997) 863-886.

[6] J.J. Moreau, Numerical aspects of the sweeping process, Comput. Methods Appl. Mech. Engrg. 177 (1999) 329-349.

[7] L. Paoli, Time discretization of vibro-impact, Philos. Trans. Roy. Soc. London Ser. A 359 (2001) 2405-2428.

[8] J.-C. Paumier, Y. Renard, Surface perturbation of an elastodynamic contact problem with friction, Eur. J. Appl. Math. 14 (2003) $465-483$. 